\title{
良心、轉診和醫生協助自殺
}

\author{
Kevin Wm. Wildes, S. J.
}

\section{摘要 :}

諸如醫生協助自殺這樣的實踐，即使合法，也會 引起一系列經常為人們所忽視的道德衝突。最近一項 關於監生協助死亡的建議就是這方面的一個例子，該 建誐呼嶺那些反数自殺的䁂生將病人轉移給另外更富 有同情的醫生。然而這項建議沒有考虑那些在道義上 反對這縻做的醫生們的道德憂虑。

關鍵詞：合作，安樂死，內在惡，實質合作，計劃，轉 診，寬容

Kevin Wm, Wildes, S.J., Ph.D., Center for Ethics, Medicine, and Public Issues, Baylor College of Medicine, One Baylor Plaza, Houston, Texas 77030, U.S.A.

原载：The Journal of Medicine and Philosophy $18: 323-328 ， 1993$.

《中外醫學哲學》I：1（1998年2月）：頁151 157。 
關於安樂死和醫生協助自殺的爭議並不限於它們在法律上 是否應該受到寬容, 而且還在於它們在實踐中推行之後, 如何 讓那些視其為罪惡的人們避免道德上的憂慮。作為合作行惡的 特例, 協助自殺和安樂死引起許多問題, 尤其需要指出的是其 中三個問題：1) 如何區分這種合作的類別？2）能否避免這種 合作, 而不致引起更為嚴重的惡 ? 3) 要求這種合作的壓力是 否反映出我們道德多樣性的社會的一種特別的不宽容?

在其最近的文章中，Timothy Quill，Christine Cassel 和Diane Meier建議那些反對協助自殺的醫生將提出這種要求 的病人轉給 “更樂於接受” 的醫生（p. 105），這些作者同其 他許多人一樣没有認識到在道德上反對協助自殺的性質及其深 度。他們寫道 :

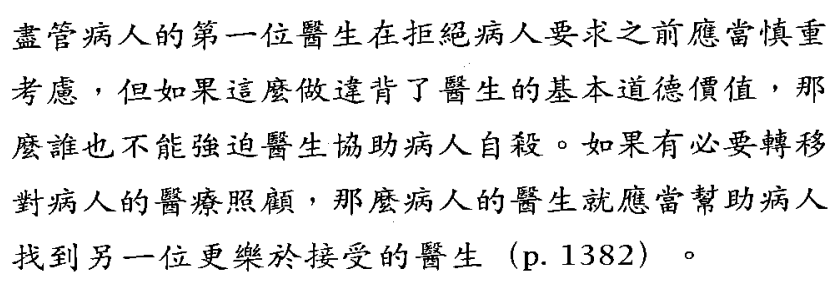

對許多人來説, 這種轉診的要求無異於合作從事惡的計劃, 是 對轉診醫生的良心的冒犯。對那些將自殺理解為内在的惡的人 來説, 避免參與這種合作的願望並不只是一個愛好問題。

將一種行動理解為 “內在惡”, 對此有些人可能感到奇 怪。但是, 存在一些具有固有的道德惡的行動（如謀殺、自 殺、通姦), 這種觀念在西方道德思想中一直頗具影響力。認 為這些行動是錯誤的，因為它們將惡引入世問或影響當事人的 德性從而違背了道德律。最為重要的是, 即使這些行動的後果 是好的，它們仍然是錯誤的。

由於合作本身是惡，因而參與一些活動的合作就是錯誤 的, 這一觀念似乎在協助自殺以外的領域得到了廣泛承認。試 想人們認為恐怖分子要想殺死無辜平民是錯誤的。再設想恐怖
分子找到一個人來購買一件不受控制的電子裝置, 而該裝置是 恐怖分子針對其他國家火車站所預謀的一項爆炸案的必須品, 於是這人得出結論認為向恐怖分子提供這種裝置是不合適的。 那麼這是否意味着可以這樣説 : “盡管我發現我自己在道德上 不能向你提供這些装置, 但讓我告訴你在那裏可以買到它。我 怎能阻止你購買你所需要的材料或將自己的道德觀強加於你 呢? ”這種情景不是用來測試常見的道德直覺, 而是表明不道 德的合作這種觀念。在大多數人對道德問題的尋常態度上, 捲 入某些活動是錯誤的, 因為這些活動是錯誤的。當這些活動具 有內在的惡時，這種合作的惡甚至變得更加棘手。

當一個社會中人們對甚麼是道德上的惡具有不同的理解 時, 那麼對甚麼是不道德的合作也就會有不同的理解。再者, 人們難以避免與人們判斷為道德上惡的人和事打交道。因此, 人們必須小心不被他人編入策劃的大網, 以免以高昂的道德代 價才得趘脱。當一個人認為提供幫助是合作行惡時, 那麼他就 必須採取措施使他人不要期望得到這種幫助。

羅馬天主致道德神學對合作提供了經典的説明。羅馬天主 教道德神學在 “宗教” 的道德説明中具有幾乎獨一無二的特 點, 那就是它試圖將其論證不依賴於上帝的啟示。諭證取決於 正確的推理。這裹無須為這種有爭議的主張進行辯護, 當某些 活動內在的惡，人們又生活在一個許多人不但不認識這些惡， 而且要人們參與這些惡的社會中時, 只要羅馬天主㸚道德神學 對合作和道德妥協的性質提供一種理解也就足矣。這一傳統是 將對行動者的意願和其他人的意願的關注, 與對在世界上產生 某些事態的關注結合在一起來考虑。

從亞里士多德開始這一傳統就將實質合作和形式合作進行 了區分, 以便對不同類型的合作進行評估。一個行動的 “形 式”結桪是通過行動的意向或行動的性質而認識的。行動的意 向是旨在達到的事態, 包括達到它所採取的步驟（Boyle）。 
有些行動被看作惡，無論行動的意向如何。實質合作就是通過 本性並非道德上錯誤的行動來幫助他人從事惡的行動 (Healy, p. 103)

由於有些自殺是內在地惡的行動，轉診行動，雖然“本性 並非道德上錯誤”，但也是實質上的惡，因為採取轉診的意向 是使病人能夠完成內在地惡的行動。Quill等人所提出的難題 有點像要求一個友人你是否可用他的房子通姦。這個友人有可 能由於他認為這種活動是一種惡而拒絕你的要求。在這種情況 下，道德不允許同一個友人提供另一個人的名字和可能的通姦 者可進行惡的行動的另一個地點的地址。

實質合作可以通過“計劃”這種語言加以理解。在合作中 一方被要求參加另一方的計劃。形式的合作是完全參與另一個 人的計劃, 有理解有意向, 而實質合作則是諸種計劃的魯合。 在羅馬天主教道德神學中人們發現，若存在疑慮或正當的理由 時可以允許實質合作。例如，一個人可能陷入這樣的情況，壤 事 (不管是甚麼) 將會發生，拒絕合作將給自己帶來更大的傷 害。Edwin Healy 就提供了下面這則例子：

$\mathrm{N}$ 是藥舖的掌䅔, 當他在晚間行將打烊時, 一位男人 進門用槍對準他的腦袋説：“我曾在此發誓如果她繼 續對我扯謊, 我將殺掉她, 現在我就要這麼做。給我 拿些砒霜來, 否則我就讓你的腦袋開花。”如果 $N$ 不 能阻止這個䦗入者實行他的計劃, 且又找不出藉口拒 綛提供砒霜或其他毒菜, 那麼他向其提供毒菜是情有 可原的。在這些情況下，他就沒有義務為拯救另一個 人的生命而瀻牲自己的生命 (p. 105)。

在病人要求協助死亡的情況下，醫生受到傷害的情況並不存 在, 因而合作的理由也就不能成立。

如果實質合作“尚欠貼切”，那麼另外還有一些嚴畫理由 為合作解脱。Healy提供的一個例子是：一個人在出售避孕藥
具的藥店工作。根據傳統的理解, 避孕藥具被視為潛在地幫助 内在惡的行為。也許有嚴肅的理由支持在該藥店工作的職員 （如為養家糊口）。在 Healy 看來, 此時的合作就應當被允 許。另外一些恪守傳統的人會爭辯説, Healy有失謹慎。然而 Healy 也建議這位職員另擇職業以免陷入困境（Healy.p 105）。但按照 Quill 等人起草的標準, 沒有合適的理由能為 該種合作開脱。

對那些理解自殺是一種惡的醫生來説, 問題是如何對參與 這種惡計劃的要求做出反應。一種辦法是醫生講明拒絕參與的 活動範圍 (如協助自殺、人工流產、撤除對處於持續性植物狀 態的病人的治療）。由於世俗的道德話語依賴於道德行動者的 權威 (Engelhardt，1991），對病人不應當隱眻醫生或醫療 機構的觀點 (Wildes)。用普通世俗的話來説，人們可能認 為，隱脼其對協助自殺觀點的醫生捲入了欺騙行為。作為對這 種欺騙的反應，國家可有普通的、世俗的道德根據來迫使醫生 或醫院配合病人之要求 (如新澤西高等法院的判例) 。但是, 如果醫生隨意迎合病人的要求, 那麼這種選擇會破壞他自己的 道德計劃, 對個人喪失了正直品格, 我認為這對社會也是一種 損失。

有人也許爭辯説, 事先告知病人這種道德信念, 只能幫助 令人反感的活動。這種反對意見認為, 將人們的道德操守公佈 於眾實際上會增加自殺行為。然而, 這種反對意見所依據的是 因果性推理, 以及要求人對其使之更容易發生的任何後果負責 的道德責任觀點。雖然認為自殺是在道德上惡的醫生關注行動 的後果 (如增加自殺), 他們也關注他們在產生世界上惡的事 態中的作用。在這種道德推理的傳統中, 個人與他所產生的後 果的關係便具有決定意義。

人們可能直接促成某種行動 (形式合作) 並對其負責。人 們也可能間接地參與某種行動 (實質合作)。在這種間接的合 
作情況下，行動的情境必須予以考慮才能評價參與者的責任的 性質。在對行動者的道德責任進行評估時，這種道德推理的傳 統, 將我的計劃和其他人的計劃加以區分。這種區分也一直是 世俗道德話語的一部分 (Williams, pp. 100-118)。一個人 參與其他人計劃的程度 (形式、實質，或根本沒有）是一個良 心問題，人們必須根據所持有的道德價值的等級來確定。一個 人對其他人計劃應負的責任將取決於合作的程度和從事這種合 作的情況而定。在道德多樣性中，真正的寬容應當允許醫生和 醫院採用不同的醫護方法, 以使其生活完全與他們自己的道德 價值相一致（Wildes）。

協助死亡和安樂死的可行性將迫使那些具有反對這些做法 的道德信念的人形成關於哪些合作是正當的、為甚麼正當、何 時正當等的考慮。再者，這些考慮必須用普通的世俗的術語加 以清楚表達，如果這些考慮有助於避免在具有不同道德觀的人 們之間引起誤會的話。我們只是剛剛開始在某些醫療領域内理 解生命偷理信念的多樣性和合作的道德障礙 (如醫生轉診)。

\section{參考文獻}

Engelhardt, Jr., H.T.: 1991, Bioethics and Secular Humanism: The Search for a Common Morality, SCM Press, London.

Healy, E.F.: 1956, Medical Ethics, Loyola University Press, Chicago.

Quill, T.E., Cassel, C., Meier, D. : 1992, 'Care of the hopelessly ill: Proposed clinical criteria for physician-assisted suicide', The New England Journal of Medicine, 327, 1380-1384.

Superior Court of New Jersey, Appelate Division, Re Requena, 442-486, decided, October 6, 1986.

Wildes, S.J., K.W.: 1991, 'Institutional integrity: Approval, toleration, and holy war or "always true to you in my fashion" ' , The Journal of Medicine and Philosophy 16, 211-220.

Williams, B.: 1973, "A critique of utilitarianism" in Utilitarianism: For and Against, J.J.C. Smart \& B. Williams (eds.), Cambridge University Press, Cambridge, pp. $77-150$

〔左傅長譯，邱仁宗校〕 